\title{
THE RELATIONSHIP BETWEEN EXPOSURE TO ANTI- SMOKING CAMPAIGN, KNOWLEDGE, FAMILY SUPPORT, AND SMOKING HABIT, AMONG MALE WORKERS IN EAST BORNEO, INDONESIA
}

\author{
Nida Amalia, Wongsa Laohasiriwong, \\ Teerasak Phajan, Somsak Pitaksanurat \\ Faculty of Public Health, Khon Kaen University, Thailand
}

\begin{abstract}
BACKGROUND: Indonesia has the highest (46.16\%) prevalence of smokers among the ASEAN countries. Some anti-smoking measures had been implemented. However, little was known for their effect. This study aimed to determine the prevalence of smoking, and the relationship between exposure to anti-smoking campaign, knowledge, family support, and smoking habit, among male workers in East Borneo, Indonesia.

SUBJECT AND METHODS: This was a cross sectional study conducted in Samarinda, East Borneo, Indonesia. A sample of 311 male workers was selected at random from 10 subdistrics in Samarinda. The dependent variable was smoking behavior. The independent variable included exposure the anti-smoking campaign, knowledge about the damaging effect of tobacco smoking, and family support. A structured questionnare was developed to collect the data. A logistic regresion was used to analyze the data.

RESULTS: The prevalence of smokers was $45.6 \%(95 \% \mathrm{CI}=40.09$ to 51.23). Un-exposure to anti-smoking campaign $(\mathrm{OR}=2.24,95 \% \mathrm{CI}=1.10$ to 4.68; $\mathrm{p}=0.032$ ), lacking in knowledge of the health damaging effect of tobacco smoking such as mouth and throat cancers $(\mathrm{OR}=2.43 ; 95 \% \mathrm{CI}=1.16$ to $5.06 ; \mathrm{p}=0.018)$, and weak family support $(\mathrm{OR}=2.07 ; 95 \% \mathrm{CI}=1.09$ to 4.50; $\mathrm{p}=0.006)$, were all associated with an increased probability of smoking.

CONCLUSION: Nearly half of the Indonesian male workers living in Samarinda were smokers. Un-exposure to anti-smoking campaign, lacking in knowledge of the health damaging effect of tobacco smoking such as mouth and throat cancers, and weak family support, were all associated with an increased probability of smoking. The government should increase the frequency of anti-smoking campaign and improve its access.
\end{abstract}

Keywords: anti-smoking campaign, smoking behavior, male workers 